\title{
Review of: "Additional Greenhouse Gas Emissions and Offset Potential from Sugarcane Straw Recovery for Bioenergy Production in Southern Brazil"
}

Orhan sevimoglu

Potential competing interests: The author(s) declared that no potential competing interests exist.

Dear Editor.

This paper is about the GHG emission from harvesting and soil emission from sugarcane agricultural area which it is title "Additional Greenhouse Gas Emissions and Offset Potential from Sugarcane Straw Recovery for Bioenergy Production in Southern Brazil".

"The rules of spelling and punctuation should be revised throughout the article.

The representation of some numbers is incorrect and the units do not follow the spelling rules.

Reference numbers are not sequential. The rules of the journal should be examined. It should be revised accordingly.

Whether the use of reference [3] is appropriate, it should be re-evaluated. Additional reference should be added

'biomass-to-bioenergy systems' must be double quotes. Its use or representation in a sentence should be re-evaluated.

If the reference [5-9] covers the entire paragraph, it should be added to the end of the paragraph. If the inside information is covered separately, relevant references should be distributed at the end of the related sentences it covers.

"The soil is classified as a Eutroferric Red Latosol (Haplustox, USDA Soil Taxonomy)." Needs may be reference and it should be changed in the expression.

"18th $(08 \mathrm{~mm})$," should be $(8 \mathrm{~mm})$.

"In each treatment ( 3 replicates)" should be expressed better.

"bioenergy generation (explained below)" should be expressed better.

"[20][27]" must be in the same parentheses.

the residual material (residual cellulignin)" if there is only one material, "residual cellulignin" should be writte.

"The $\mathrm{CO} 2$ emission factors calculated according to the methodological approach "Tool to calculate the emission factor for an electricity system, version 04.0 and earlier" approved by the Clean Development Page 10/20 Mechanism (CDM), Executive Board are intended to estimate the contribution, in terms of $\mathrm{CO} 2$ 
emission reductions, from a project that generates electricity for the grid [30]." Should be re-written.

"There was significant difference between these two treatments only on days 07 and $09(P<0.05)$," what is 07 and 09 .

Figure 1: 01 hectar should be 0.1 hectar $(100 \mathrm{~m} \times 100 \mathrm{~m})$

Figure 3. Is that right Word to use in the figure "avoided". Consider an other Word.

“1 MJ $=0.000277778 \mathrm{KWh}$ ” does realy need to write here.

Some references are used multiple times in the manuscript. This needs to be taken into account.

"(diesel use)" should be use in the sentences.

The following article can be integrated into Introduction, paragraph 3.

“Orhan Sevimoğlu, Wolfgang F. Rogge, Seasonal variations of PM10 - Trace elements, PAHs and Levoglucosan: Rural sugarcane growing area versus coastal urban area in Southeastern Florida, USA. Part II: Elemental concentrations, Particuology, Volume 46, 2019, Pages 99-

108,https://doi.org/10.1016/j.partic.2019.05.001."

Overal, the manuscript proofreading should be done. The above mentioned arrangements should be made. Then the result of the editor's evaluation can be published.

Assoc. Prof. Dr. Orhan Sevimoglu

Faculty Member

Gebze Technical University

Environmental Engineering Department

41400 Gebze/KOCAELI

Tel: +90 (262) 6053143

Fax:+90 (262) 6533145

www.gtu.edu.tr 